\title{
To Assess the Behavior towards the Society among the Students in Saveetha Dental College
}

\author{
Keerthana. $\mathrm{R}^{1 *}$, Dr. Karpagam Krishnnamoorthy ${ }^{2}$
}

\section{ABSTRACT}

Aim: A study of behavioral pattern of the students of Saveetha Dental College towards the society. Objective: To analyze the behavior towards the society among the students in Saveetha Dental College. Background and reasons: Culture is a set of values, beliefs and behavior shared by a group of people. It is a set of human made objectives and subjective elements: it is transmitted through generations. Culture makes individual to conform to norms. The orientation of society in which individuals practice a particular culture may differ. Individualistic pattern of culture always emphasizes individual's privacy and improvement more than anything else. It stresses the individual uniqueness. To study the social orientation of the group and to improve their culture value towards the society.

Keywords: Behavior, Society, Students, Saveetha Dental College

Social psychology is the scientific study of how people's thoughts, feelings, and behaviors are influenced by the actual, imagined, or implied presence of others. In psychology, social behavior is referred to human behavior.

A culture is a way of life of a group of people--the behaviors, beliefs, values, and symbols that they accept, generally without thinking about them, and that are passed along by communication and imitation from one generation to the next. Cultures are typically divided into two categories: collectivist and individualist. Individualist cultures, such as those of the United States and Western Europe, emphasize personal achievement regardless of the expense of group goals, resulting in a strong sense of competition. Collectivist cultures, such as those of China, Korea, and Japan, emphasize family and work group goals above individual needs or desires. This study will explain the type of social behavior of individuals.

\footnotetext{
${ }^{1}$ First year BDS, Saveetha Dental CollegeSaveetha Dental College, India

${ }^{2}$ Assistant Profressor, Saveetha Dental CollegeSaveetha Dental College, India

*Responding Author

(C) 2016 I R Keerthana, K Krishnnamoorthy; licensee IJIP. This is an Open Access Research distributed under the terms of the Creative Commons Attribution License (http://creativecommons.org/licenses/by/2.0), which permits unrestricted use, distribution, and reproduction in any Medium, provided the original work is properly cited.
} 


\section{MATERIALS AND METHODS:}

A survey based questionnaire was used to evaluate the type of social behavior of individuals. A total of 54 people individuals studying BDS from Saveetha dental college were selected. They were made to sit comfortably and were given the questionnaire to fill. The results were collected and tabulated.
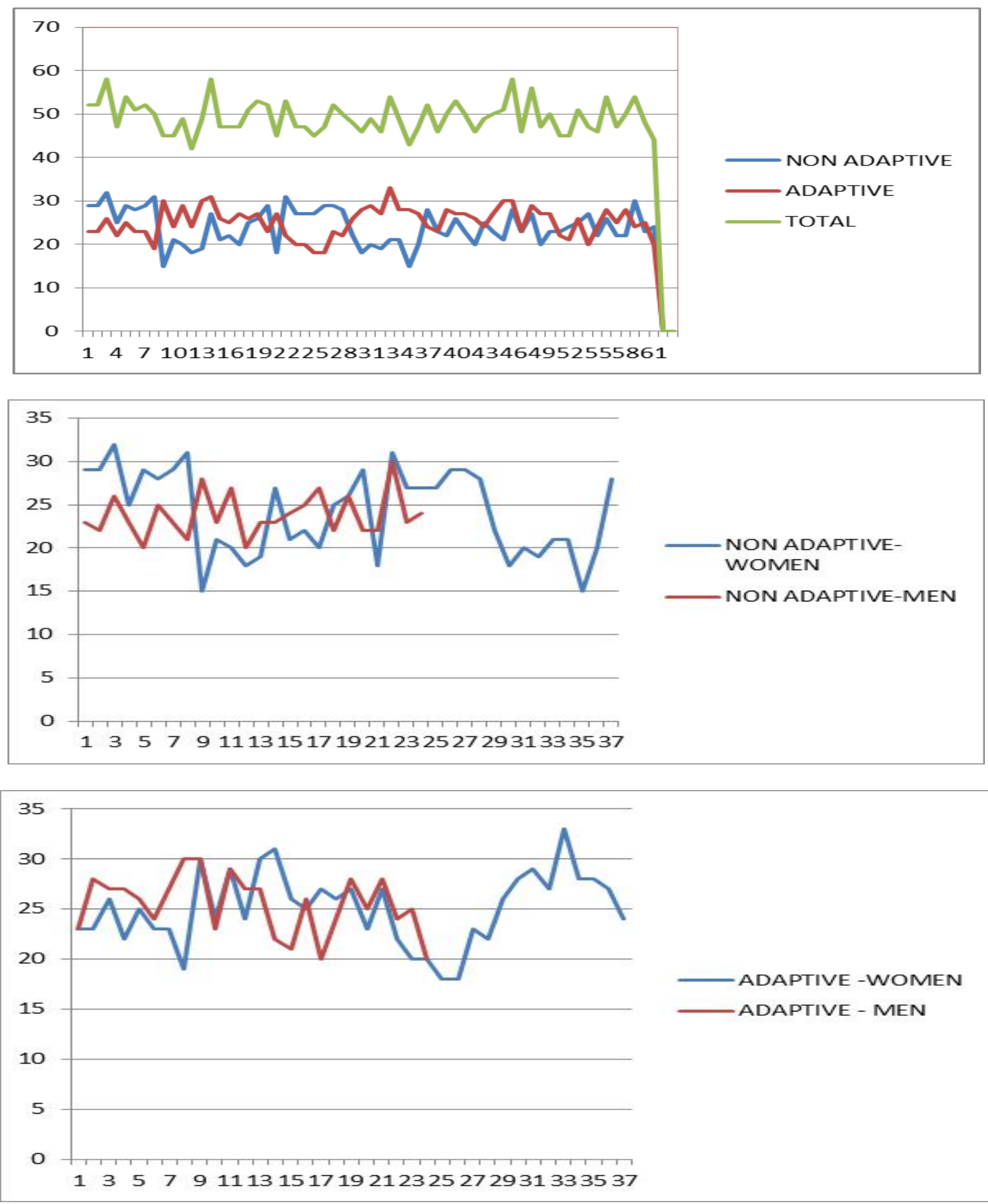

(c) The International Journal of Indian Psychology, ISSN 2348-5396 (e)| ISSN: 2349-3429 (p) | 134 
To Assess the Behavior towards the Society among the Students in Saveetha Dental College

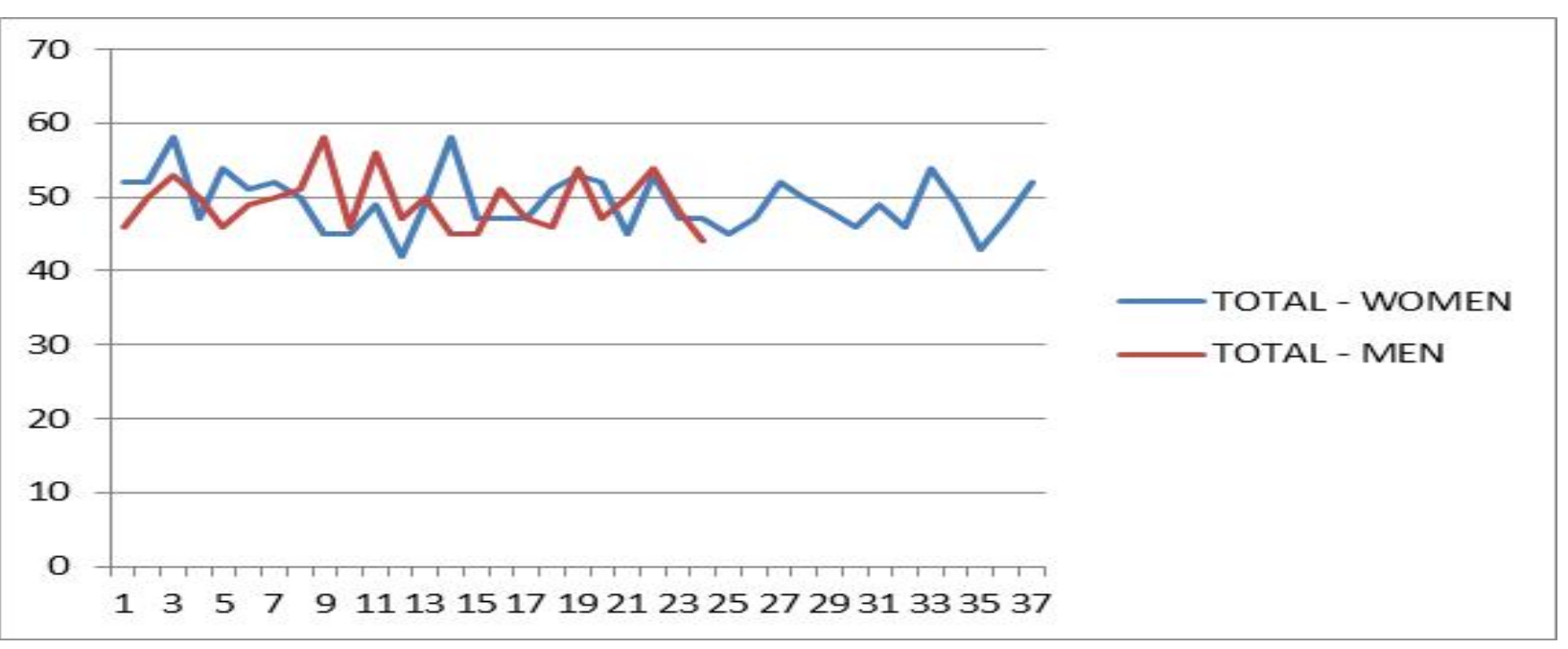

\section{SOCIAL BEHAVIOUR}

\section{Non adaptive}

29

29

32

25

29

28

29

31

15

21

20

18

19

27

21

22

20

25

26

29

18

31

27

27

27

29

\section{Adaptive}

Total

52

52

58

47

54

51

50

45

45

49

42

49

58

47

47

47

51

53

52

45

\begin{tabular}{|l|l|}
\hline 53 \\
\hline 47 \\
\hline 47 \\
\hline 45 \\
\hline 47 \\
\hline
\end{tabular}


To Assess the Behavior towards the Society among the Students in Saveetha Dental College

\begin{tabular}{|l|l|l|}
\hline Non adaptive & Adaptive & Total \\
\hline $\mathbf{2 9}$ & 23 & 52 \\
\hline $\mathbf{2 8}$ & 22 & 50 \\
\hline $\mathbf{2 2}$ & 26 & 48 \\
\hline $\mathbf{1 8}$ & 28 & 46 \\
\hline $\mathbf{2 0}$ & 29 & 49 \\
\hline $\mathbf{1 9}$ & 27 & 46 \\
\hline $\mathbf{2 1}$ & 33 & 54 \\
\hline $\mathbf{2 1}$ & 28 & 49 \\
\hline
\end{tabular}

\section{SOCIAL BEHAVIOUR-1}

\begin{tabular}{|c|c|c|}
\hline 15 & 28 & 43 \\
\hline 20 & 27 & 47 \\
\hline 28 & 24 & 52 \\
\hline 23 & 23 & 46 \\
\hline 22 & 28 & 50 \\
\hline 26 & 28 & 54 \\
\hline 23 & 27 & 50 \\
\hline 20 & 26 & 46 \\
\hline 25 & 24 & 59 \\
\hline 23 & 27 & 50 \\
\hline 21 & 30 & 51 \\
\hline 28 & 30 & 58 \\
\hline 23 & 23 & 46 \\
\hline 27 & 29 & 56 \\
\hline 20 & 27 & 47 \\
\hline 23 & 27 & 5 \\
\hline 23 & 22 & 45 \\
\hline 24 & 21 & 45 \\
\hline 25 & 26 & 51 \\
\hline 27 & 20 & 47 \\
\hline 22 & 24 & 46 \\
\hline 26 & 28 & 54 \\
\hline \begin{tabular}{|l}
22 \\
\end{tabular} & 25 & 47 \\
\hline 22 & 28 & 50 \\
\hline 30 & 24 & 54 \\
\hline 23 & 25 & 48 \\
\hline 24 & 20 & 44 \\
\hline \begin{tabular}{|l|} 
High:32 \\
\end{tabular} & \begin{tabular}{|l|} 
High:33 \\
\end{tabular} & High:59 \\
\hline
\end{tabular}




\section{DISCUSSION:}

A total of 61 individuals were assessed. Out of 61,37 were females and 24 were males. The non-adaptive character of females and males were same 23\%.The adaptive character of male $28 \%$ and female $26 \%$.The total average of non-adaptive character was $23 \%$ and adaptive character was $27 \%$.The total average was $49 \%$.The highest value of non-adaptive character in female was 31 and male was 30 and the lowest value of female was 15 and male was 21 .The highest value of adaptive character in female was 31 and male was 30 and the lowest value in females was 18 and male was 20 The highest value of total non-adaptive and adaptive in female was 58 and male was 59 and the lowest value in females was 42 and males was 44 The highest value of non-adaptive among all the individuals was 32 and the lowest value was 15 The highest value of adaptive among all the individuals was 33 and the lowest value was 18 The highest value of total non-adaptive and adaptive among all the individuals was 59 and the lowest value was 42.

\section{CONCLUSION:}

The crime rates like murder, rape, theft etc., in our country are increasing. This is due to the nonadaptive character of people. All the people equally possess non adaptive and adaptive character. These non-adaptive characters may be due to many reasons like family background, work environment, psychiatric issues etc., The non-adaptive characters can be changed by influencing on these factors. The adaptive character of people should be increased so as to reduce the crime rates.

\section{REFERENCE:}

Antisocial Behavior in School: Strategies and Best Practices. Walker, Hill M.; And Others Journal of Educational Psychology, Vol 90(2), Jun 1998, 202-209.

New Trends in Measuring Environmental Attitudes: Measuring Endorsement of the New Ecological Paradigm: A Revised NEP Scale Riley E. Dunlap1,†, Kent D. Van Liere2, Angela G. Mertig3 and Robert Emmet Jones4

Social relationships and motivation in middle school: The role of parents, teachers, and peers. Wentzel, Kathryn R.

The self and social behavior in differing cultural contexts. Triandis, Harry C. Psychological Review, Vol 96(3), Jul 1989, 506-520.

How to cite this article: R Keerthana, K Krishnnamoorthy (2016), To Assess the Behavior towards the Society among the Students in Saveetha Dental College, International Journal of Indian Psychology, Volume 3, Issue 3, No. 9, DIP: 18.01.167/20160303, ISBN: 978-1-36513820-1 